\title{
Analysing admission control for AODV and DSR routing protocol in mobile ad-hoc network
}

\author{
Folayo Aina $^{1}$, Sufian Yousef ${ }^{2}$, Opeyemi Osanaiye ${ }^{3}$ \\ ${ }^{1}$ School of Psychology and Computer Science, University of Central Lancashire, Preston, United Kingdom \\ ${ }^{2}$ Department of Engineering and Built-in-Environment, Anglia Ruskin University, Chelmsford, Essex, United Kingdom \\ ${ }^{3}$ Department of Computer Engineering, Nile University of Nigeria, Abuja, Nigeria
}

\begin{tabular}{l} 
Article Info \\
\hline Article history: \\
Received Jun 8, 2021 \\
Revised Aug 8, 2021 \\
Accepted Aug 27, 2021 \\
\hline
\end{tabular}

Keywords:

Admission control

MANET

QoS

Routing protocol

\begin{abstract}
The widespread deployment of mobile ad-hoc network (MANET) in the areas of agriculture, military defence, weather forecasting and disaster control has necessitated the implementation of admission control within a network for a guaranteed quality of service (QoS). Admission control organises traffic flows to ensure the network medium is fairly shared among various nodes in the network. Various admission control algorithms have been proposed in the literature, using different metrics and parameters to achieve different admission control quality. In this work, we propose an Admission control in mobile ad-hoc network routing (ACMANR) using both bandwidth capacity and resource estimation to achieve a good QoS. Furthermore, we analyse the behaviour of two well-known routing protocols in wireless network, ad hoc on-demand distance vector (AODV) and dynamic source routing (DSR), in our proposed admission control algorithm. Simulation results obtained from our proposed admission control algorithm using OPNET show that AODV routing protocol had a better throughput while DSR produced a better delay with lower overhead in MANET. Our proposed approach also shows better performance in terms of throughput and delay when compared with the stateof-the-art admission control routing using AODV and DSR.
\end{abstract}

This is an open access article under the CC BY-SA license.

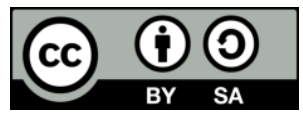

\section{Corresponding Author:}

Opeyemi Osanaiye

Department of Computer Engineering

Nile University of Nigeria

Plot 681 Cadastral Zone C-OO, Research and Institutional Area, Jabi Airport Road Bypass, Abuja, Nigeria

Email: opeyemi.osanaiye@ nileuniversity.edu.ng

\section{INTRODUCTION}

In recent years, MANET have received much attention due to its deployment in the areas of disaster site, battle fields, search and rescue operation. A significant feature of an ad-hoc network is the absence of backbone infrastructure or a base station to enhance its communication [1]. Therefore, for communication to be possible in an ad-hoc network, nodes communicate directly with each other without the need to go through an intermediary. Notwithstanding its numerous benefits and applications, the deployment of MANET has brought about various issues that needs to be addressed. Prominent among these are its dynamic topology, inability to predict the topology, non-reliability of wireless medium and constrained nodes [2]. This has therefore resulted in various reliability issues such as node failure, link failure, and breakage of route (especially during congestion) [3], [4]. The routing protocol to be deployed must therefore compensate for issues posed by the ad-hoc network to achieve network efficiency.

The function of an admission control is to decide on the type of application to be admitted into a network. This could be highly consequential in situations where there are high level of constrained resources 
within the network. It does not guarantee any node resources if there are limited available bandwidth within the network, to avoid network congestion or interference. Admission control ensures that the admission of a new flow into a given resource constrained network does not violate previous rules set by the network admission flow. The rules made by a network administrator could either be qualitative or quantitative. Admission control also tends to control the allocation and usage of network resources, especially for applications requiring additional service. Therefore, admission control allows component such as bandwidth to be used only when it is available, in order to avoid constraining the network resources.

There are three different approaches to admission control; the parameter-based, the endpoint-based, and the measured-based. The parameter-based admission control function by computing the total network resources required to support a set of flows, giving a flow priori characteristic. The endpoint-based approach, on the other hand, allow users to make decision whether or not to join the network using a probe packet. Finally, the measured-based admission control totally relies on the measurement of traffic load before an admission decision can be made. In this study, we adopt the measured based admission control that use the bandwidth capacity and resource estimation to guarantee and maintain a high QoS. Furthermore, we will observe and analyse the behaviour of our proposed admission control algorithm when AODV and DSR routing protocols are introduced in MANET. Finally, we will compare our proposed approach with the stateof-the-art admission control routing using AODV and DSR to observe their throughput and delay.

As earlier stated, the main function of an admission control scheme is to ensure the admission of a new traffic flow into a network, provided it does not violate the rules that may exist within the network. According to [5], [6], for an admission control scheme to be successfully implemented, there are several requirements that must to be fulfilled [7]; these includes:

a. Robustness: the implemented admission control scheme on the network must ensure that the necessary

QoS requested is provided. The network quality must also be robust towards traffic heterogeneity, heavy load, and time scale.

b. Resource utilization: the implemented admission control scheme must maximize resource utilization with respect to the QoS constraint of the admitted flow.

c. Implementation: the deployment cost of an admission control scheme must also be put into consideration. Its cost must be less than its benefit.

It is also important to note that while deploying an admission control scheme, focus should not be directed on only the gateway for QoS to be maintained in MANET. There must be adequate provision for locations that are hotspot centred, especially those locations around the MAC layer [8]. All these requirements were considered during the designing of our proposed admission control algorithm to achieve a good and guaranteed QoS in MANET.

In the literature, admission control have been implemented in MANET. The authors in [9] made use of a sender based admission control to regulate real-time UDP traffic. Makrakis [10] also proposed a QoS routing algorithm that depends on an effective admission control while the authors in [11] proposed a measured-based admission control algorithm. It is important to note that while proposing a measured-based admission control, there cannot be an accurate measurement in its design for MANET considering the unpredictable movement of mobile host [12].

\section{RESEARCH METHOD}

\subsection{Bandwidth capacity}

Bandwidth capacity is the amount of traffic that can be transmitted by a network without causing either a traffic degradation or affecting other flows transmitting within the network [13]. When the capacity of the channel is accurately determined, it ensures an easy deployment of the admission control scheme on the network to prevent network congestion within MANET [8]. Due to the fact that mobile nodes share the wireless network medium based on contention, there is a relationship between the capacity of a channel and the bandwidth of the channel. This is expressed as;

$$
\sum^{n} B i \leq c / a
$$

where; $n=$ the number of nodes sharing the wireless channel

$\mathrm{B}=$ Bandwidth of the node $\mathrm{i}$

$\mathrm{C}=$ Capacity of the wireless channel

$1 / \alpha=$ Channel utilization rate

A simulation to estimate the value of $\alpha$ was first conducted, thereafter, two algorithms were used to calculate the bandwidth on each node. OPNET was used to simulate our design and the parameters used is presented in Table 1. To address the control traffic's influence on data packet transmission, an amount of 
control packet that is enough to serve 10 data sessions in MANET is produced and the mobile node density is changed in different simulations. We simulated the scenario with 10, 15, and 20 nodes sharing channel. Each node forwards data packets to a randomly selected neighbour node on an equal probability basis. Figures 1-3 show the results for the average data packet delivery ratio, average throughput on each node, and average end-to-end delay with different traffic load and node density value.

Figure 1 shows that the packet delivery ratio declines with an increase in the number of nodes and the same also applies in Figure 2. The sudden performance degradation shows that wireless network with shared channel has certain rate of utilization. Its value is determined by the access channel mechanism, number of active node and traffic pattern. Therefore, an increase in the node density results in the decrease in channel utilization $(\alpha)$.

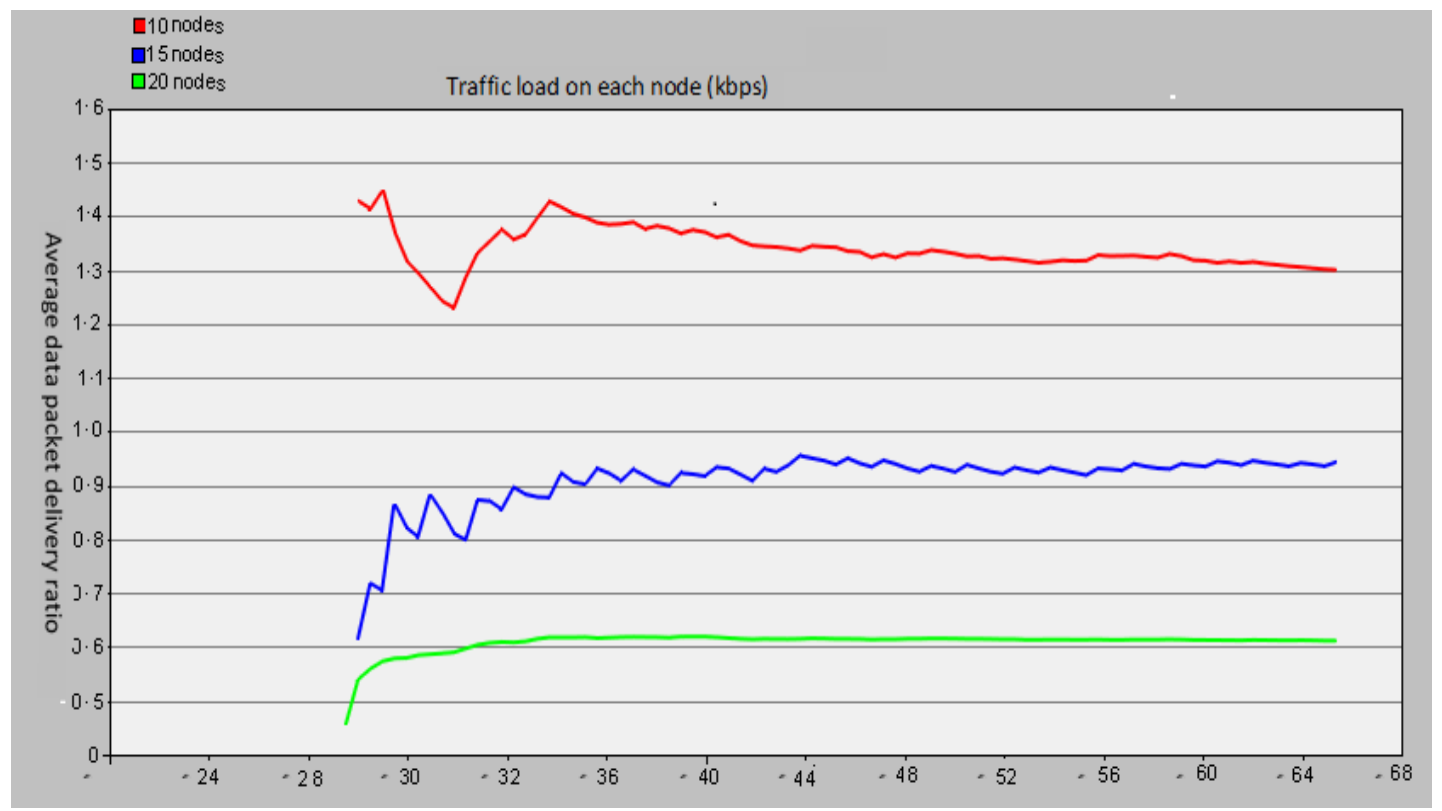

Figure 1. Average packet delivery ratio vs traffic load

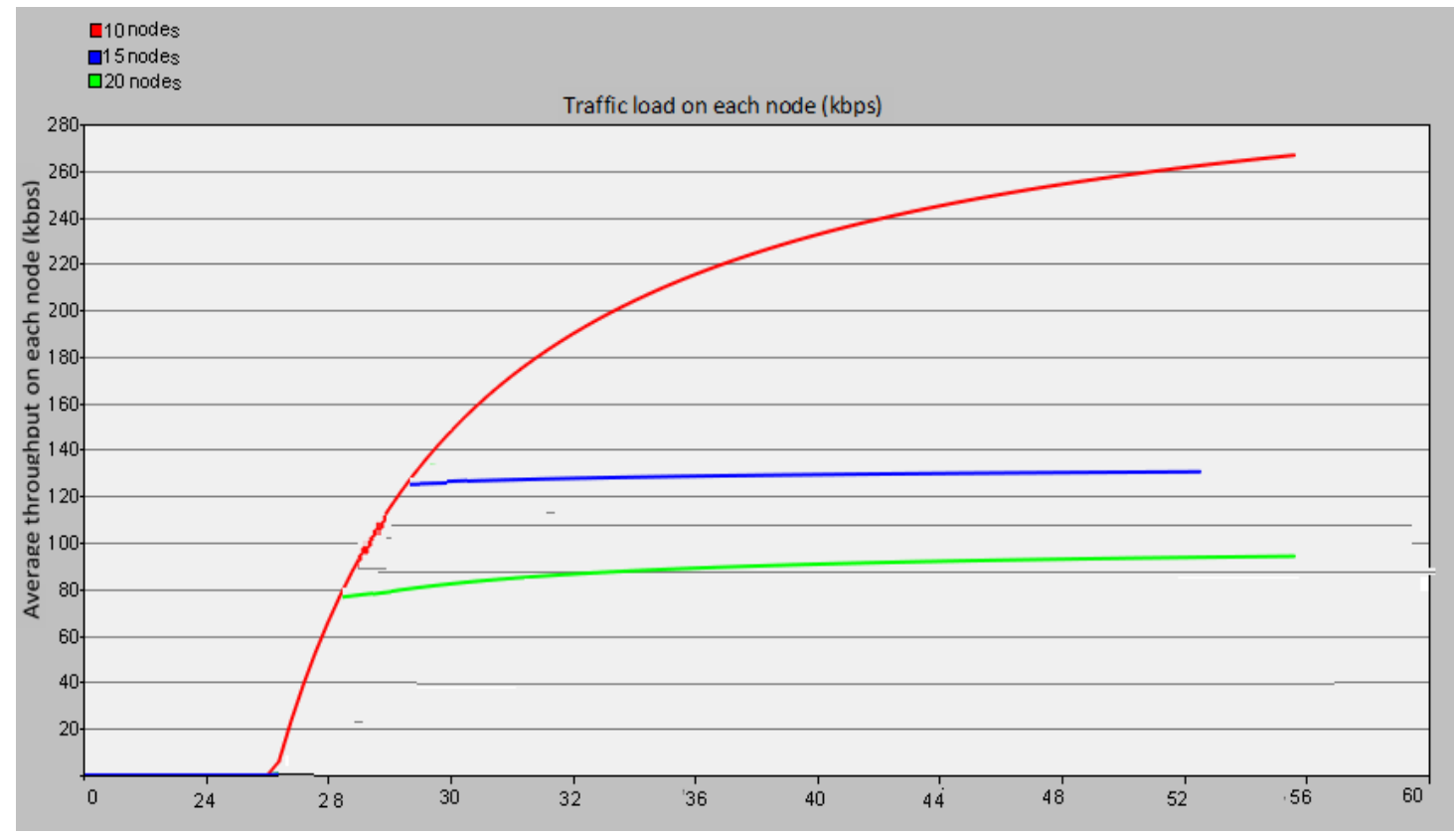

Figure 2. Average throughput on each node vs traffic load 


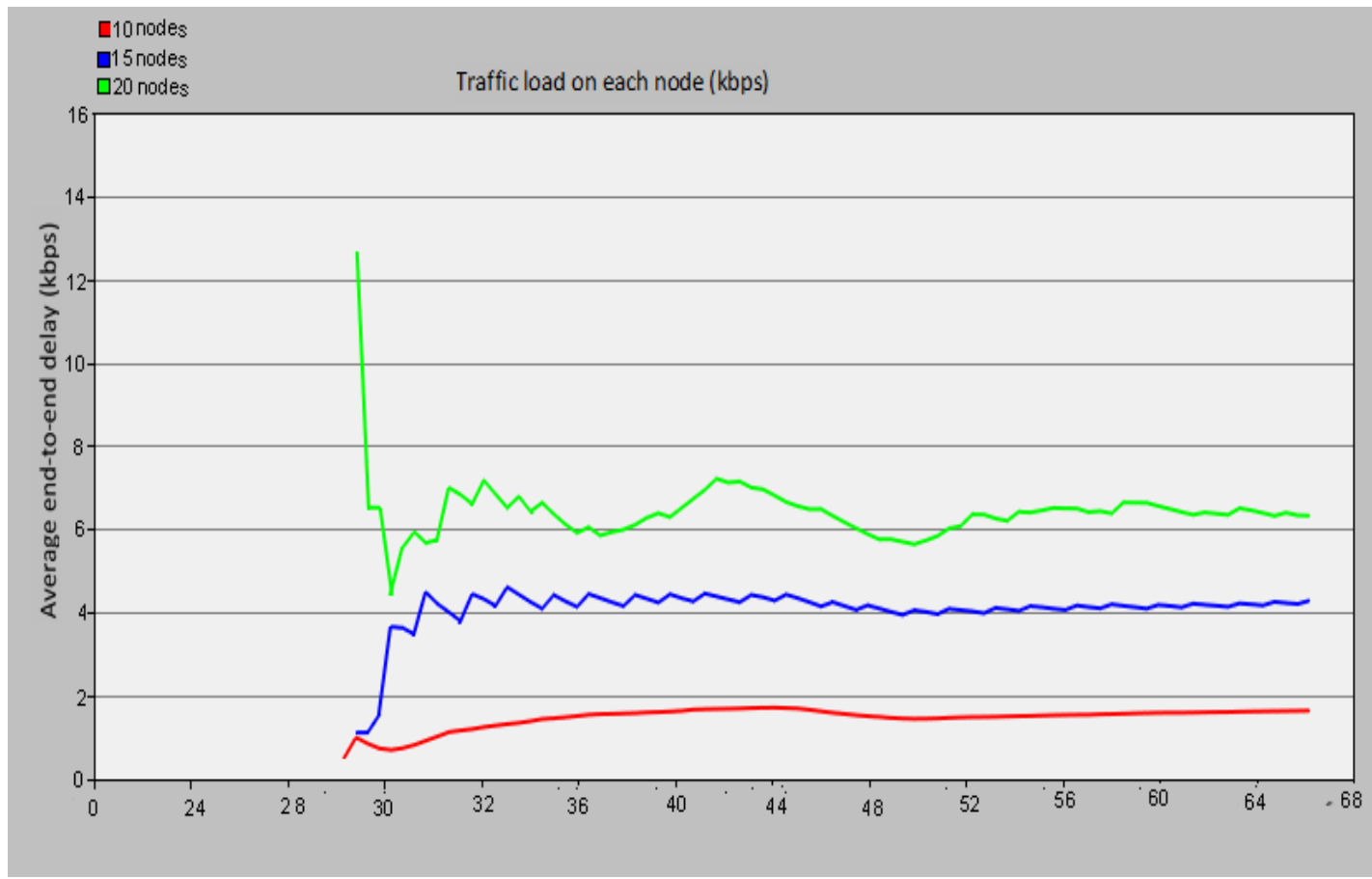

Figure 3. Average end-to-end delay vs load

Table 1. Simulation parameters

\begin{tabular}{|c|c|c|}
\hline $\mathrm{S} / \mathrm{N}$ & Parameter & Value \\
\hline 1. & Mobile nodes deployed & 50 nodes \\
\hline 2. & Transmission Range & $250 \mathrm{~m}$ \\
\hline 3. & MAC Layer Protocol & IEEE 802.11 \\
\hline 4. & Packet Size & 1024bytes \\
\hline 5. & Buffer Length & 512 byte \\
\hline 6. & Traffic rate & $64 \mathrm{kbps}$ \\
\hline 7. & Channel Capacity & $2 \mathrm{Mbps}$ \\
\hline 8. & Routing Protocol & AODV/DSR \\
\hline 9. & Topology size & $1000 \times 1000$ \\
\hline 10. & Simulation Time & 1 hour \\
\hline 11. & Mobility & Random Way Point \\
\hline
\end{tabular}

\subsection{Bandwidth estimation algorithm}

Two possible bandwidth estimation algorithms have been investigated. The channels busyness ratio in MANET and the current loss rate. The former emulates a TCP connection by measuring the actual throughput within the network, while the latter estimates the current loss rate, thereby deriving a bandwidth estimation rate from the lost packet [8], [14], [15].

\section{Channel Busyness Ratio in MANET:}

As observed in Pokhrel, et al. [16], in a slot, we could possibly have three different kind of slots; an empty slot, successful transmission, and an occupied slot causing collision. Giving that Pi , Ps and Pc are the probabilities that the observed slot is any of the three. Similarly, let T_suc and T_col be the average time period associated with one successful transmission and one collision. These can therefore be expressed as shown in below;

$$
\begin{aligned}
& T_{\text {suc }}=T_{\text {rts }}+T_{\text {cts }}+T_{\text {data }}+T_{\text {ack }}+3 T_{\text {sifs }}+T_{\text {difs }} \\
& T_{\text {coi }}=T_{\text {rts }}+T_{\text {cts timeout }}+T_{\text {difs }}=T_{\text {rts }}+T_{\text {eifs }}
\end{aligned}
$$

The successful probability transmission of the frame is equivalent to the packet transmission because of no hidden terminal. Therefore, the following equations can be obtained: 


$$
\begin{aligned}
& P_{i}=(1-p t)^{n} \\
& P_{s}=n p_{t}(1-p t)^{n-1} \\
& P_{c}=(1-p i-p s)
\end{aligned}
$$

The definition of the channel idle ratio $(\mathrm{Ri})$, channel busy ratio $(\mathrm{Rb})$ and channel utilization ratio (Rs) is also as shown in:

$$
\begin{aligned}
& R_{i}=p_{i} \sigma / p_{i} \sigma+p_{s} T_{\text {suc }}+p_{c} T_{\text {coi }} \\
& R_{b}=\left(1-R_{i}\right) \\
& R_{s}=p_{s} T_{\text {suc }} / p_{i} \sigma+p_{s} T_{\text {suc }}+p_{c} T_{\text {coi }}
\end{aligned}
$$

Where $\sigma$ is the time slot length.

\section{Packet loss rate Estimation:}

This is the second bandwidth estimation algorithm that estimates the current loss rate while deriving a bandwidth estimation rate from the lost packet. According to [14], it is not trivial to estimate the loss rate on a given path. Savage [17] in his work developed a TCP based tool for measuring the rate of packet loss between pairs of host. Therefore, it is not necessary to convert the loss rate to determine the throughput because the loss rate can be evaluated directly.

In MANET environment, a routing protocol ensures that a source finds a path to forward traffic to its destination. For communication to occur within a network, a routing protocol must be deployed. Due to the unpredictable nature of MANET, the routing protocol deployed must be very quick to adapt to changes, especially during congestion or link failure, which may result in data loss. The aim of routing protocols in MANET is to guarantee an efficient and reliable path, therefore in this work our focus is on reactive routing protocols.

Reactive routing protocols were designed to reduce the cost of storage and bandwidth attributed to table driven protocols. Reactive routing computes its route based on demand, and are only established when it is required between the source node and the destination node. The established routes are created and maintained in two phases, namely; route discovery and route maintenance. The route discovery occurs ondemand by flooding the route request (RRQ) packets throughout the network. As soon as a route is found, the destination responds with a routereply (RREP) which contains the route information transverse by the RREQ. An example of reactive routing protocol in MANET is AODV and DSR.

AODV protocol uses both hop count and shortest path to the destination when routing packet within the network. By deploying AODV to route traffic in MANET, the sending node begin by initiating a route discovery in order to set up a route path to the destination. The AODV does this by using a RREQ and RREP message system. The RREQ, whose aim is to discover a route towards a giving destination, is broadcasted by the source node towards its immediate neighbour. When the neighbour receives the request, it broadcasts the RREQ message further to their immediate neighbours and this broadcast continues until the packet gets to its destination [18]. When the destination receives the RREQ message, it sends a RREP through the path where the route request transverse through. This reply is however sent as a unicast to the source node. The path is set-up by the RREP by updating the routing table generated at the intermediate node on the transverse path. Once a RREP is received, the source node begins the transmission of its first packet [19]-[21]. Other properties of AODV includes, hop-by-hop routing, sequence number and the use of periodic beacon. The destination sequence number is used to frequently ensure a loop free network. Therefore, AODV is often referred to as a combination of DSR and DSDV routing protocols.

The DSR routing protocol exhibit similar properties posed by the AODV by making use of source routing. DSR is an on-demand reactive protocol that does not use periodic advertisement, but only computes the route discovery when necessary, before maintaining them thereafter. Both DSR and AODV routing protocols can be deployed in MANET [22], [23].

The aim of this work is to implement our proposed admission control and tests its performance by using existing on-demand routing protocol; AODV and DSR. We observe and compare the behaviour of these two protocols using network metrics such as throughput, delay and network load.

Admission control is performed at the route discovery stage during the set-up or repair of data transmission. The sender issues a RREQ containing the bandwidth requirement [23]. Once a node receives 
the RREQ requirement, it first of all calculate its own available bandwidth, thereafter, it decides to accept and forward the RREQ if the node has enough available bandwidth space. If the RREQ is beyond the capacity of a giving node, the node will deny the admission of the RREQ by discarding the request, thereby, preventing it from forwarding any form of request. For a successful RREQ, once a node receives a RREP, this means that the route has enough bandwidth and can be reserved for a new session. Subsequently, if a node in a given session fails to receive data packet for a certain period of time, or if it receives a route error (RERR), the bandwidth that has been reserved initially will be released. This same procedure will be performed if a source node refreshes the route or if it rediscovers a new route by sending a RREQ message.

\section{SIMULATION AND RESULTS}

The simulation of both AODV and DSR routing protocols with admission control in mobile ad-hoc network routing (ACMANR) is conducted in order to evaluate and observe the performance of these protocols under the bandwidth capacity and estimation algorithm. We deploy MANET and conducted two different simulations to test the two different routing protocols. In the simulation, a randomly selected node issues a RREQ packet with a bandwidth request of $64 \mathrm{kbps}$. If a route is discovered that has enough bandwidth to accommodate a bandwidth of $64 \mathrm{kbps}$, the source begins to send data through that route until the simulation terminates. Otherwise, if there is a bandwidth constrain to accommodate the $64 \mathrm{kbps}$ data packet, the request will be rejected. This prevents the network channel from been over-utilized. Each node in our simulation moves freely and independently with similar speed. Random way point mobility model was also deployed in our simulation. Random way point allows a node to randomly select its destination. It therefore moves in the direction of the destination with uniformly chosen speed which is between a minimum and a maximum speed. Once its destination is reached, the node stays there for a pause time, after which it moves on thereafter. The minimum speed chosen in our simulation is $0 \mathrm{~m} / \mathrm{s}$ while the maximum speed is 20 $\mathrm{m} / \mathrm{s}$. Pause time was set to 0 in order to observe the performance under high mobility.

\subsection{Channel utilization parameter}

The channel utilization for this work was carried out using OPNET simulation tool. The parameters used for the simulation are as follows.

- Throughput: This is the ratio of the total packets sent to the amount received correctly which is often measured in bits per seconds (bit/s or bps) and in some other times, data packets per time slot ( $\mathrm{p} / \mathrm{s}$ or $\mathrm{pps}$ ) [24]. Determining the throughput of a network tends to help in revealing the reliability of the routing protocol used.

- End-to-end delay: This is the time taken for a packet to be transmitted across the network from the transmitter to the receiver during the simulation [25], [26]. It is the sum of the delays encountered by the packets or traffic flow at each node along the path which can be measured by the length of the path and the sojourn time at each node along the path [27]. End-to-end delay analysis is a very important element to measure network performance in MANET [28].

- Network load: This is the total amount of traffic received by the entire WLAN BSS from the higher layer of the MAC that is accepted and queued for transmission [29], [30].

\subsection{Result and analysis}

The Figure 4 shows the throughput, using the time average to compare the AODV and DSR routing protocols, under our proposed bandwidth capacity and estimation admission control algorithm. From Figure 4, it is observed that the throughput of AODV routing protocol is greater than the throughput of DSR under our proposed bandwidth capacity and estimation admission control scheme. Therefore, AODV shows a higher level of throughput compared to DSR.

Figure 5 shows the delay observed between AODV and DSR routing protocols with our proposed bandwidth capacity and estimation admission control implementation. It can be observed that the delay difference between the two protocols is not significant, however, AODV has a higher delay as compared to the DSR.

Figure 6 shows the network load observed between the AODV and DSR routing protocols with bandwidth capacity and estimation admission control implementation. It can be observed that the AODV routing protocol utilizes more of the network resources than the DSR. Therefore, AODV has a higher network load capacity usage as compared to DSR.

\subsection{Discussion and performance evaluation}

In order to demonstrate and validate the performance of our proposed protocol, ACMANR, we compared it with some admission control protocols that exists in the literature. All the admission control 
protocols have been simulated using either AODV or DSR routing protocol as shown in Figure 7. Figure 7 (a) shows the throughput comparism of our admission control protocol, ACMANR, against other admission control protocols using AODV routing protocol. Results from Figure 7 (a) show that ACMANR outperforms other admission control protocols in terms of throughput and average time. ACMANR throughput performance was also compared with other existing admission control protocol using DSR routing protocol. The result obtained also shows that its throughput performance is higher than all the other admission control protocol. The delay of ACMANR was compared with other existing proposed admission control using both AODV and DSR routing protocol as seen in Figure 8 (a) and (b). Results from this comparison show that ACMANR has the least delay amongst other admission control protocols used for comparison. This however shows that ACMANR provides for better performance in terms of throughput and delay notwithstanding the routing protocol used.

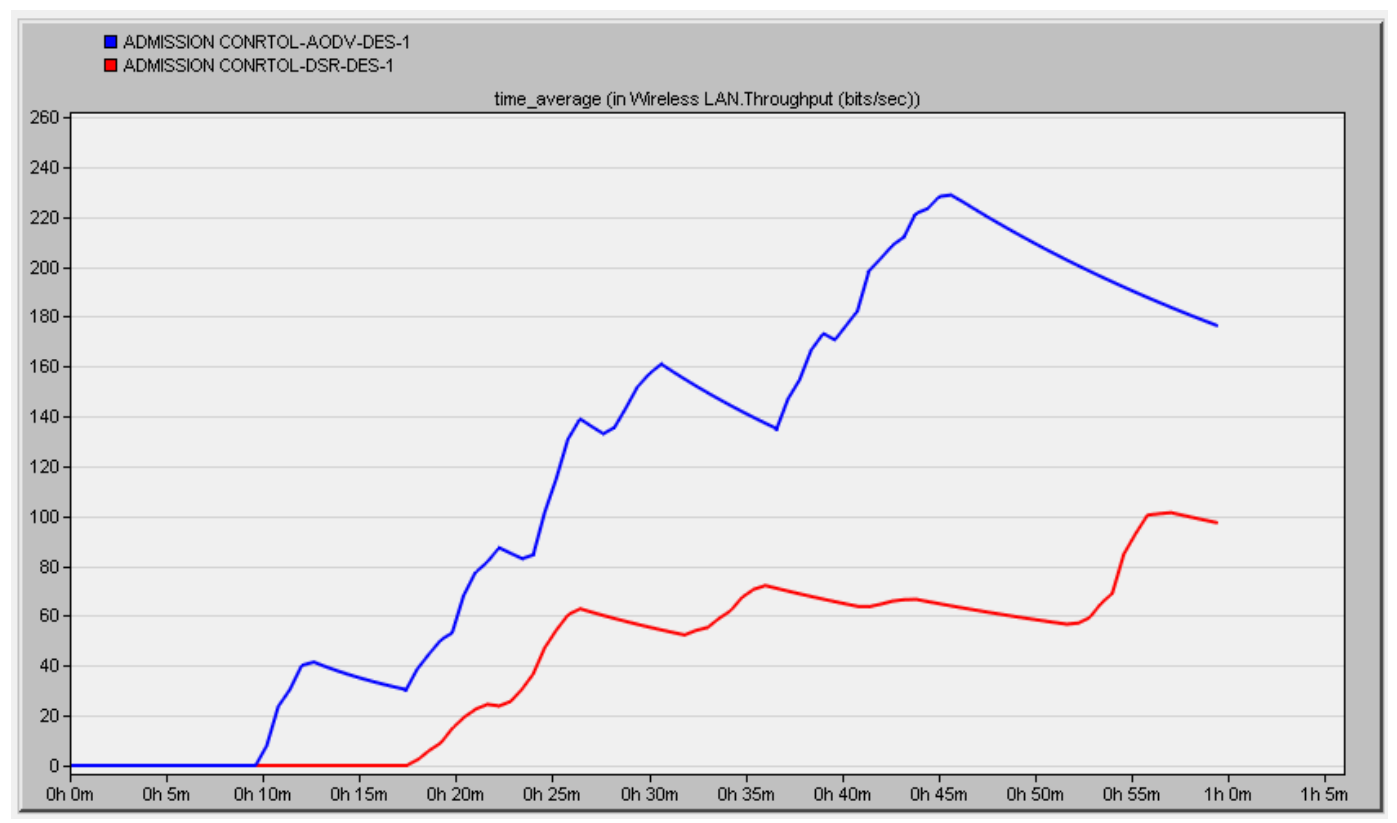

Figure 4. Throughput using the time average

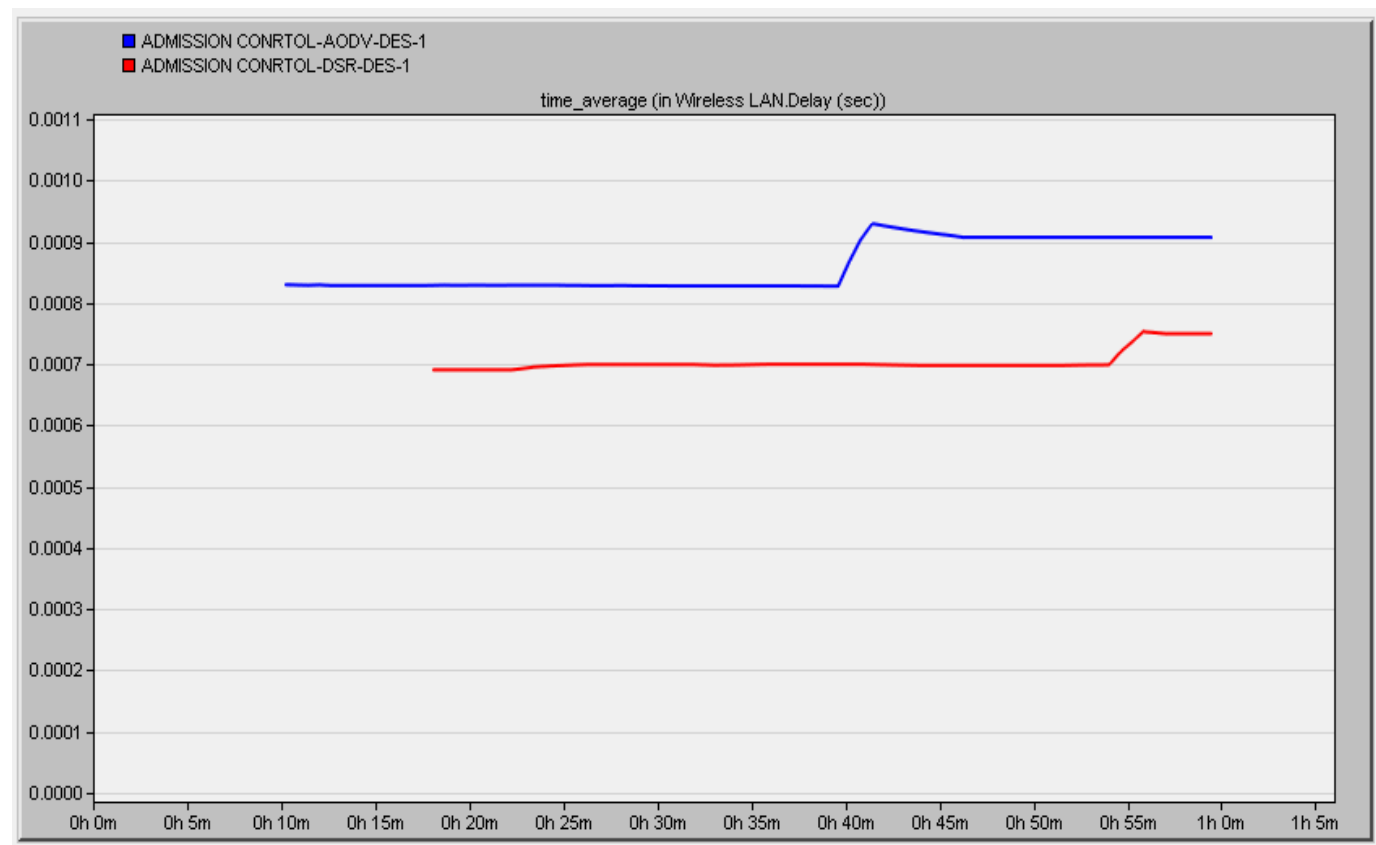

Figure 5. Delay using the time average 


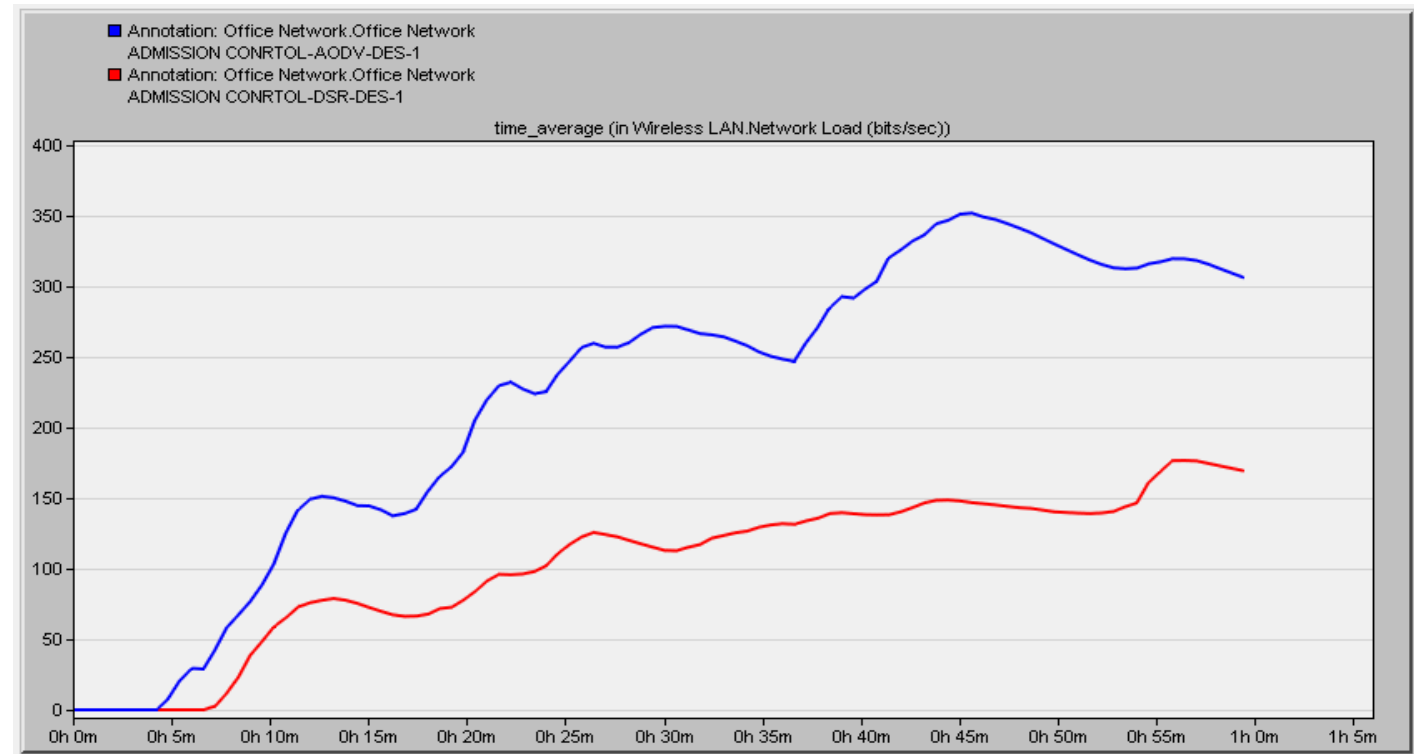

Figure 6. Network load using the time average

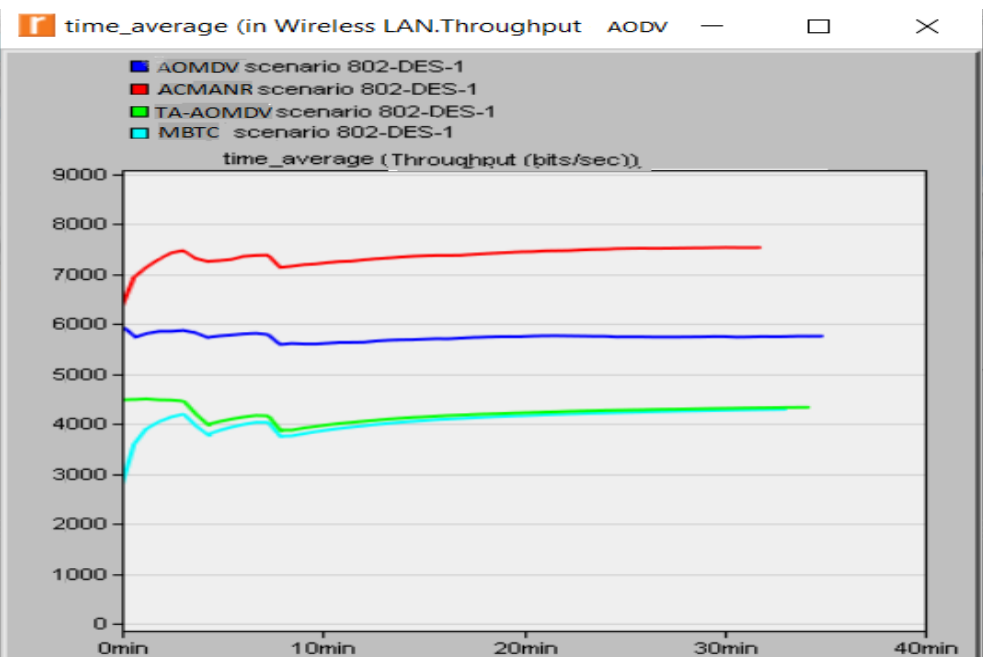

(a)

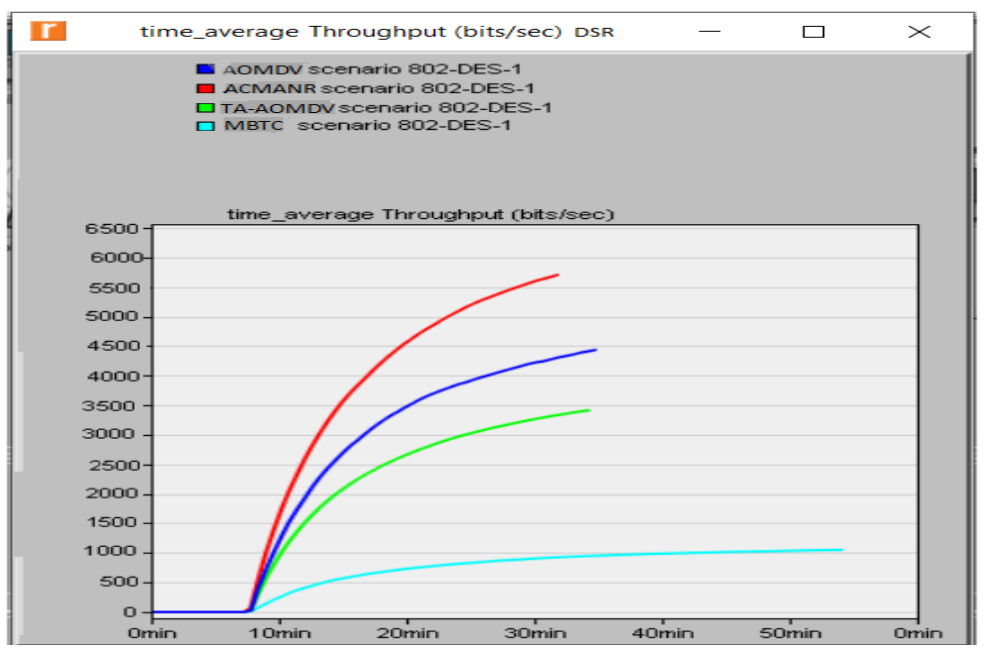

(b)

Figure 7. Throughput comparison based on routing protocol, (a) AODV, (b) DSR 


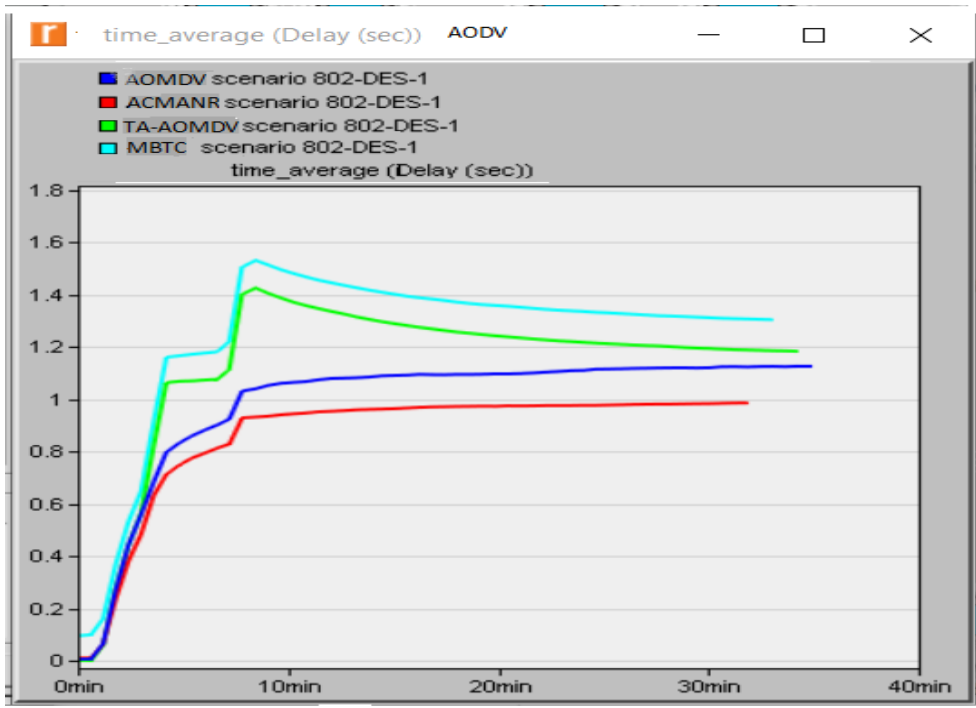

(a)

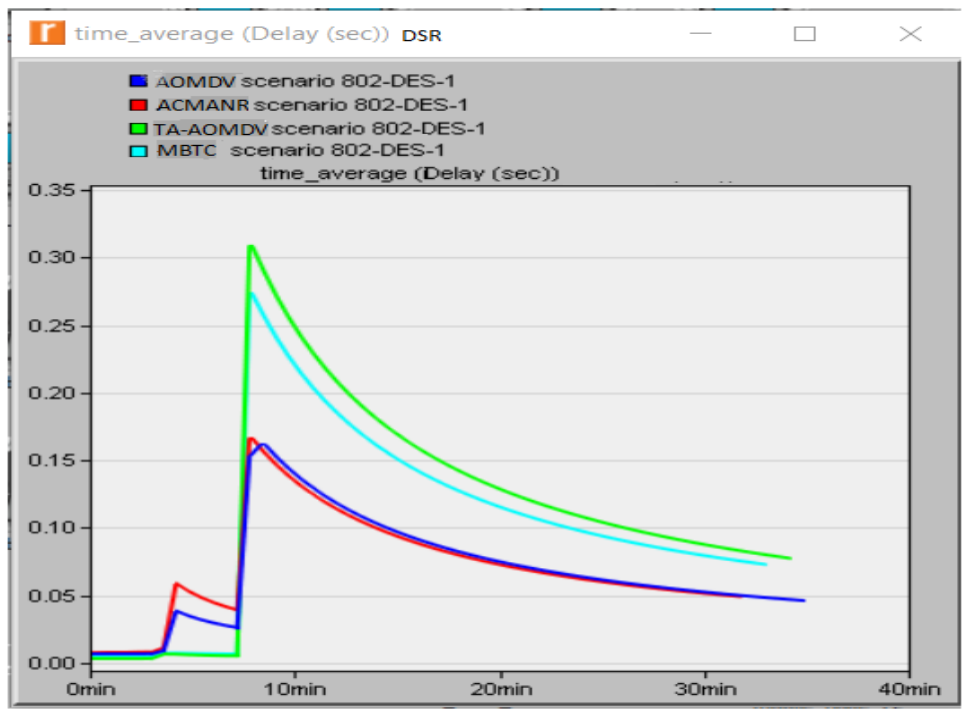

(b)

Figure 8. Delay comparison based on routing protocol, (a) AODV, (b) DSR

\section{CONCLUSION}

This work has studied the admission control in MANET by comparing two of the most prominent MANET routing protocols available in the literature. We adopted a measured based admission control approach by proposing a bandwidth capacity and resource estimated admission control algorithm, Admission control in mobile ad-hoc network routing (ACMANR). Furthermore, we analysed and studied our proposed method against the existing on-demand routing protocols. Experimental simulation, using OPNET simulation tool, was used to evaluate our proposed method in order to compare the behaviour of AODV and DSR routing protocols under bandwidth capacity and resource estimation admission control algorithm. Results from this simulation show that the AODV had a better throughput than the DSR while the DSR had a better delay value with less network utilization. Our proposed approach was also compared with the state-of-the-art admission control. Simulation results obtained show that our proposed ACMANR technique produced a better performance in terms of throughput and delay using AODV and DSR. In future, we plan to extend our evaluation to include other routing algorithms to determine the efficiency and robustness of our proposed admission control technique. 


\section{REFERENCES}

[1] D.-gan Zhang, J.-X. Gao, X.-H. Liu, T. Zhang, and D.-X. Zhao, "Novel Approach of Distributed and Adaptive Trust Metrics for MANET," Wireless Networks, vol. 25, no. 10, pp. 3587-3603, 2019, doi: 10.1007/s11276-01901955-2.

[2] D.-gan Zhang, C. Chen, Y.-ya Cui, and T. Zhang, "New Method of Energy Efficient Subcarrier Allocation Based on Evolutionary Game Theory," Mobile Networks and Applications, vol. 26, no. 2, pp. 523-536. doi: 10.1007/s11036-018-1123-y.

[3] P. Kaur and R. Singh, "A Systematic Approach for Congestion Control in Wireless Ad hoc Network Using Opnet," International Journal of Computer Applications, vol. 67, no. 22, pp. 1-8, 2013, doi: 10.5120/11524-7193.

[4] L. Khoukhi, H. Badis, L. M.-Boulahia, and M. Esseghir, "Admission Control in Wireless ad hoc networks," EURASIP Journal on Wireless Communications and Networking, vol. 1, pp. 1-13, 2013, doi: 10.1186/1687-14992013-109.

[5] D. Zhang, et al., "A Multi-Path Routing Protocol Based on Link Lifetime and Energy Consumption Prediction for Mobile Edge Computing," in IEEE Access, vol. 8, pp. 69058-69071, 2020, doi: 10.1109/ACCESS.2020.2986078.

[6] F. Aina, S. Yousef, and O. Osanaiye, "Bandwidth Estimation for Admission Control in MANET: Review and Conceptual MANET Admission Control Framework," in Proceedings of the Future Technologies Conference, 2018, vol. 881, pp. 651-671, doi: 10.1007/978-3-030-02683-7_46.

[7] K. Kavya, "A measurement based traffic admission control algorithm for resource management in IP networks," 2019 1st International Conference on Advanced Technologies in Intelligent Control, Environment, Computing \& Communication Engineering (ICATIECE), 2019, pp. 140-143, doi: 10.1109/ICATIECE45860.2019.9063786.

[8] S. K. Khangura, M. Fidler, and B. Rosenhahan, "Machine learning for measurement-based bandwidth estimation," Computer Communications, vol. 144, pp. 18-30, 2019, doi: 10.1016/j.comcom.2019.05.005.

[9] M. Mongelli, M. Muselli and M. Marchese, "A Unified View to Machine Learning and Control for Measurementbased Equivalent Bandwidth," 2020 16th International Conference on the Design of Reliable Communication Networks DRCN 2020, 2020, pp. 1-6, doi: 10.1109/DRCN48652.2020.1570609737.

[10] H. Zhou, C. Ye, Y. Duan, Q. Qi, and Y. Zhang, "Estimating End-to-End Available Bandwidth for Cyber-Physical Applications in Hybrid Networks," Wireless Internet Conference, WICON, vol. 214, pp. 197-206, 2018, doi: 10.1007/978-3-319-72998-5_21.

[11] F. Shang, D. Zhou, and D. He, "An admission control algorithm based on matching game and differentiated service in wireless mesh networks," Neural Comput \& Applic, vol. 32, no. 4, pp. 2945-2962, 2020, doi: 10.1007/s00521018-3751-3

[12] D. Salcedo, C. D. Guerrero, and R. B. M. Aguilar, "Available bandwidth estimation tools metrics, approaches and performance," International Journal of Communication Networks and Information Security (IJCNIS), vol. 10, no. 3 , pp. 580-587, 2018.

[13] L. Sharma, C. Lal, D. P. Sharma, P. Kaliyar, "Enhancing QoS for Multimedia Services Using Mobility-Aware Bandwidth Estimation Algorithm in MANETs," in International Conference on Optical \& Wireless Technologies (OWT2017), Jaipur, India, 2017, pp. 655-666, doi: 10.1007/978-981-10-7395-373.

[14] A. Ganesan, "On Some Distributed Scheduling Algorithms for Wireless Networks With Hypergraph Interference Models," in IEEE Transactions on Information Theory, vol. 67, no. 5, pp. 2952-2957, May 2021, doi: 10.1109/TIT.2021.3059719.

[15] Yazeed A. Al-Sbou, "Wireless Networks Performance Monitoring Based on Passive-Active Quality of Servive Measurement," International Journal of Computer Networks \& Communications (IJCNC), vol. 12, no. 6, pp. 15-32, 2020, doi: 10.5121/ijenc.2020.12602.

[16] S. R. Pokhrel, H. L. Vu and A. L. Cricenti, "Adaptive Admission Control for IoT Applications in Home WiFi Networks," in IEEE Transactions on Mobile Computing, vol. 19, no. 12, pp. 2731-2742, 1 Dec. 2020, doi: 10.1109/TMC.2019.2935719.

[17] A. A. Ajibesin, M. M. O. Kah, A. T. Ishaq and C. A. Ajibesin, "Performance Analysis of Topology and Destination Based Routing Protocols in Mobile Ad-Hoc Network Using NS2," 2019 IEEE 13th International Conference on Application of Information and Communication Technologies (AICT), 2019, pp. 1-6, doi: 10.1109/AICT47866.2019.8981772.

[18] K. Kavya, "A measurement based traffic admission control algorithm for resource management in IP networks," 2019 1st International Conference on Advanced Technologies in Intelligent Control, Environment, Computing \& Communication Engineering (ICATIECE), 2019, pp. 140-143, doi: 10.1109/ICATIECE45860.2019.9063786.

[19] L. Song and A. Striegel, "Leveraging Frame Aggregation for Estimating WiFi Available Bandwidth," 2017 14th Annual IEEE International Conference on Sensing, Communication, and Networking (SECON), 2017, pp. 1-9, doi: 10.1109/SAHCN.2017.7964908.

[20] I. Das, R. N. Shaw, and S. Das, "Location-Based and Multipath Routing Performance Analysis for Energy Consumption in Wireless Sensor Networks," Innovations in Electrical and Electronic Engineering, vol. 661, pp.775-782, 2021, doi: 10.1007/978-981-15-4692-1_59.

[21] M. Adil, "Congestion Free Opportunistic Multipath Routing Load Balancing Scheme for Internet of Things (IoT)," Computer Networks, vol. 184, p. 107707, 2021, doi: 10.1016/j.comnet.2020.107707.

[22] Z. Chen, W. Zhou, S. Wu and L. Cheng, "An Adaptive on-Demand Multipath Routing Protocol With QoS Support for High-Speed MANET," in IEEE Access, vol. 8, pp. 44760-44773, 2020, doi: 10.1109/ACCESS.2020.2978582.

Bulletin of Electr Eng \& Inf, Vol. 10, No. 5, October 2021 : 2667 - 2677 
[23] S. Yan and Y. Chung, "Improved Ad Hoc On-demand Distance Vector Routing (AODV) Protocol Based on Blockchain Node Detection in Ad Hoc Network," International ournal of Internet, Broadcasting and Communication, vol. 12, no. 3, pp. 46-55, 2020, doi: 10.7236/IJIBC.2020.12.3.46.

[24] B. H. Khudayer, M. Anbar, S. M. Hanshi and T. Wan, "Efficient Route Discovery and Link Failure Detection Mechanisms for Source Routing Protocol in Mobile Ad-Hoc Networks," in IEEE Access, vol. 8, pp. 24019-24032, 2020, doi: 10.1109/ACCESS.2020.2970279.

[25] O. Osanaiye, A. S. Alfa, and G. P. Hancke, "A statistical approach to detect jamming attacks in wireless sensor networks," Sensors, vol. 18, no. 6, p. 1691, 2018, doi: 10.3390/s18061691.

[26] O. A. Osanaiye, A. S. Alfa and G. P. Hancke, "Denial of Service Defence for Resource Availability in Wireless Sensor Networks," in IEEE Access, vol. 6, pp. 6975-7004, 2018, doi: 10.1109/ACCESS.2018.2793841.

[27] F. Aina, S. Yousef, and O. Osanaiye, "RAAC: a bandwidth estimation technique for admission control in MANET," Facta Universitatis, Series: Electronics and Energetics, vol. 32, no. 3, pp. 463-478, 2019, doi: 10.2298/FUEE1903463A.

[28] J. Wanguo, M. Sheng, Y. Shi, and Y. Li, "End-to-end delay estimation for multi-hop wireless networks with random access policy," Science China Information Sciences, vol. 57, no. 6, pp. 1-13, 2014, doi: 10.1007/s11432014-5103-y.

[29] F. Aina, S. Yousef, and O. Osanaiye, "RAACM: Resource Allocation for Admission Control in MANET," International Journal of Wireless Information Networks, vol. 26, no. 3, pp. 243-256, 2019, doi: 10.1007/s10776019-00432-z.

[30] D. K. Lobiyal, C. P. Katti, and A. K. Giri, "Parameter value optimization of ad-hoc on demand multipath distance vector routing using particle swarm optimization," Procedia Computer Science, vol. 46, pp. 151-158, 2015, doi: 10.1016/j.procs.2015.02.006.

\section{BIOGRAPHIES OF AUTHORS}

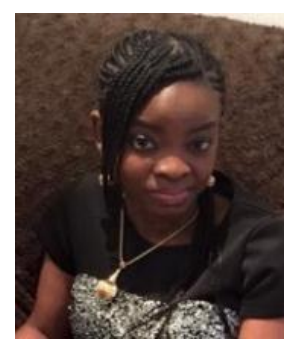

Folayo. A. Aina received the bachelor's degree in computer science from the University of Ilorin, Nigeria, in 2009, the master's degree in network systems from the University of Sunderland, UK., in 2011, and Ph.D. degree in computing in Anglia Ruskin University, Chelmsford, UK in 2020. She is currently a Lecturer at the School of Psychology and Computer Science, University of Central Lancashire, Preston, United Kingdom. Her research interests include computer networks, wireless networks, MANET, mobile communication, and network security.

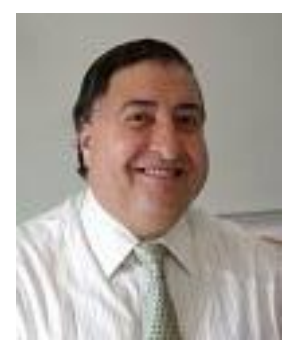

Sufian Yousef is the Director of Telecommunication Engineering Research Group (TERG), at Anglia Ruskin University. He Graduated from Baghdad University in Electronic and Electrical Engineering and completed his M.Sc. in Telecommunication Systems Management and his Ph.D. at Anglia Ruskin University in 1998. During his research, he won the Royal academy of Engineering award to be seconded to GEC Marconi for one year during 1999. His main theme of expertise is electronic design of telecommunication networks in their wired and wireless status.

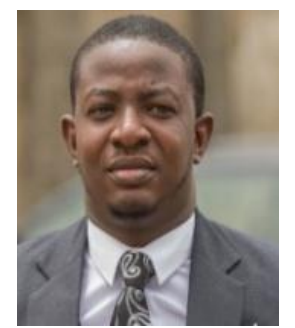

Opeyemi A. Osanaiye received the bachelor's degree in electrical engineering from the University of Ilorin, Nigeria, in 2007, the master's degree in telecommunications engineering from the University of Sunderland, U.K., in 2011, and the Ph.D. degree in electrical engineering from the University of Cape Town, South Africa, in 2016. He was a part time Lecturer with the Cape Peninsular University of Technology, Cape Town, South Africa. He was with the University of South Australia on a research exchange visit from 2015 to 2016 and a postdoctoral research fellow at the University of Pretoria, South Africa from 2017 to 2018. $\mathrm{He}$ is a Senior Lecturer with the Computer Engineering Department, Nile University of Nigeria. His research interests include, computer networks, cloud computing, wireless sensor network, fog computing, network security, voice over internet protocol technology, and cloud computing security. He is a registered COREN member and a member of IEEE. 